\title{
慢性腰痛抢よび下肢痛に対する腰椎前方固定術 - mini-ALIFの応用一
}

\author{
森本哲也, 越前直樹, 永朾 清, 小聩 久偐, \\ 乾 多人夫，㖬海总人，乾 登史考
}

\section{Lumbar Anterior Fusion for Chronic Lumbago and Leg pain: Clinical Application of the mini-ALIF}

by

Tetsuya Morimoto, Naoki Koshimae, Kiyoshi Nagata, Kunihiko Kobitsu, Takuo Inui, Hayato Toriumi, Toshitaka Inui

firom

\section{Department of Neurosurgery, Osaka Police Hospital}

We have modified the original mini-ALIF by using a cage technique to eliminate posterior fusion in patients presenting with lumbago. Twenty-eight individuals have been treated with this technique. All but 2 individuals were evaluated with discography for the responsible level suitable for discectomy and fusion. Twenty-one of the 26 patients presented with discogenic pain concomitant with the usual home pain.

A retroperitoneal approach employing a minimal opening technique was applied for all patients, after which discectomy was followed by Mayer"s original technique and cage fixation. Patients were allowed to walk on the postoperative fïst day. fitted with a soft corset.

The average follow-up period has been 14 months. Pain relief achieved excellent results in 11 , good in 14 , fair in 2 and poor in 1 . The mean improvement rate was $60.5 \%$ evaluated using the Japanese Orthopaedic Association score.

In conclusion. the present technique for the treatment of lumbar spinal disorders has proved to be safe and useful in terms of minimally invasive surgery.

Key word: ALIF, lumbar spinal disorders. discography

Spinal Surgery $17(2): 107 \sim 112,2003$

\section{はじめに}

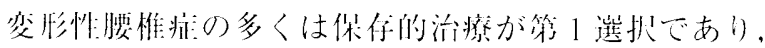

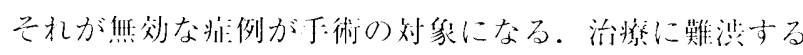

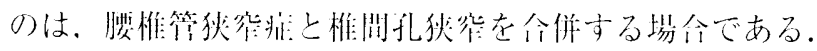
彷来は，こ机らに刘して公範州惟り切除術が・般们に施

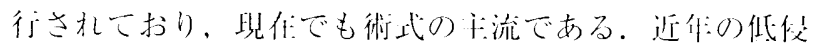

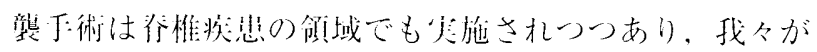

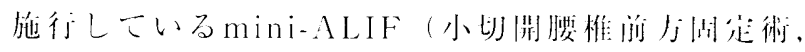

minimally invasive anterior lumbar interbody fusion)

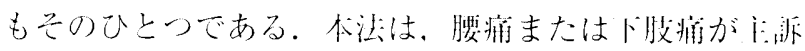

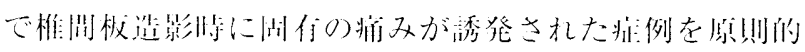
に丁術邀忍としている。

対象と方法

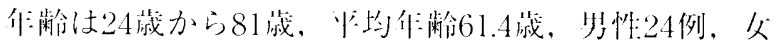

(Received : January 27, 2003, Accepted : April 4, 2003)

大阪警察病院 脳神経外科（連絡先：森本哲也, $\bar{T}$ 543-0035 大阪市天王寺区北山町10-31) Address reprint request to: Tetsuya Morimoto, M.D., Department of Neurosurgery, Osaka Police Hospital, 10-31 Kitayama-cho, Ten-noji-ku, Osaka 543-0035, Japan 


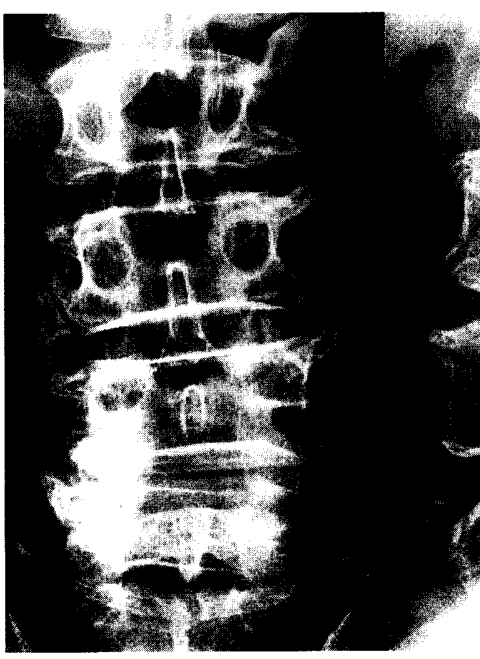

a
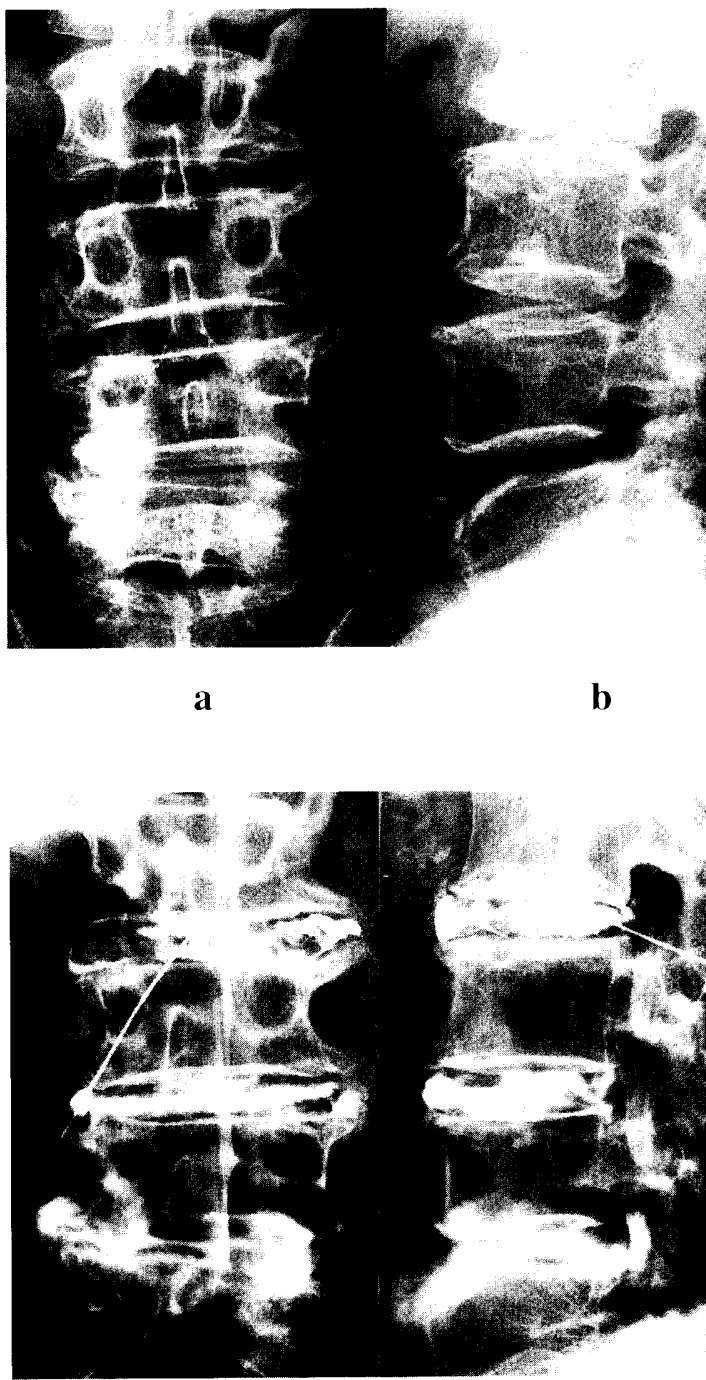

a b

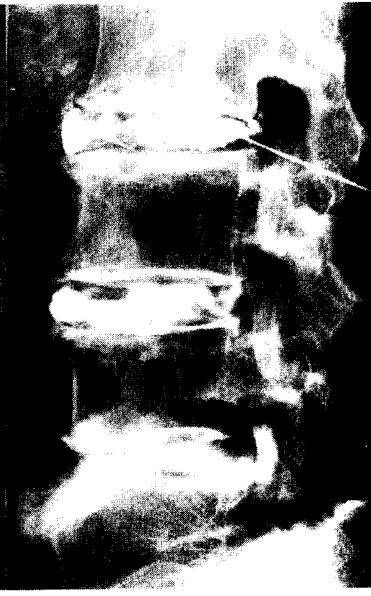

b

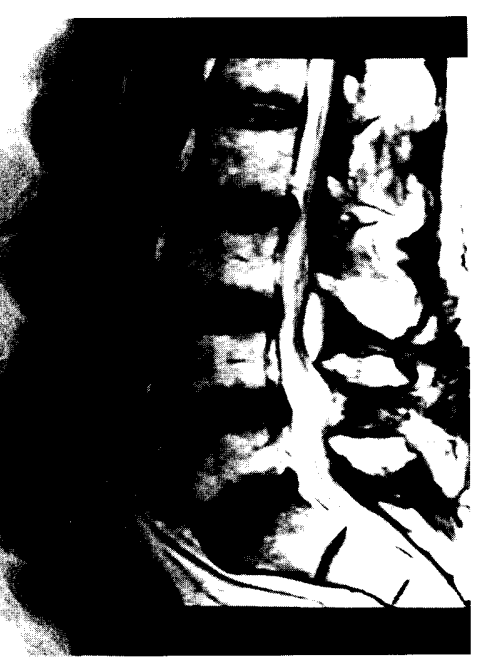

c

Fig. 1 : Plain X-ray of the lumbar spine and sagittal image of MRI. Plain radiograph indicates spur formation.

MR Image demonstrates dise bulging at L2-3 and L4-5.

性4例であった。神経注状として，企例に聩摍，16例に

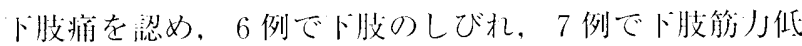

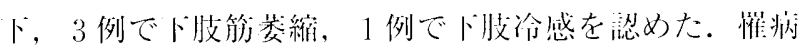

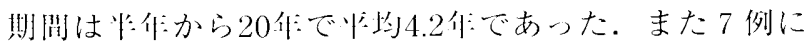

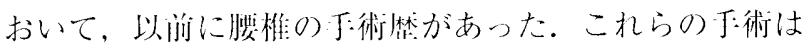
無效か知期のみ们效であった。

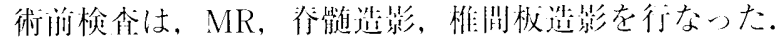

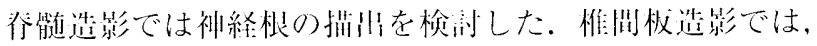

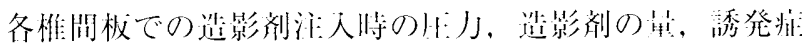

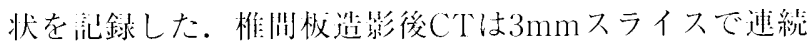

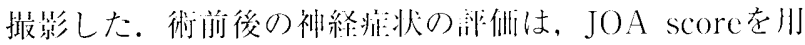

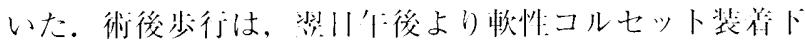
に剬始した。術後人院期间は101てであった。杴性コルセ

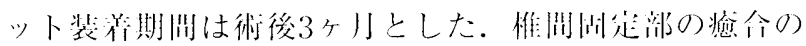

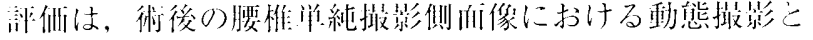

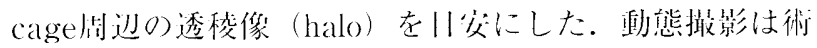

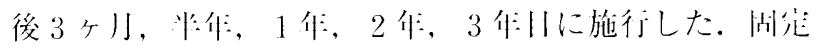

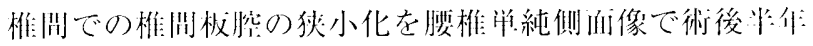
後に䧸夜した。

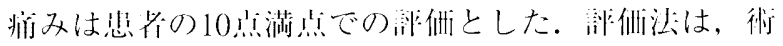

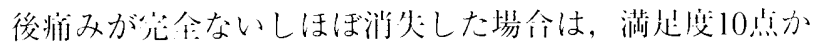

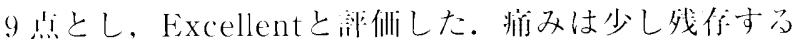

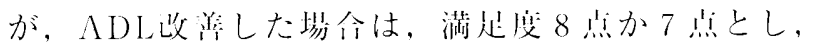

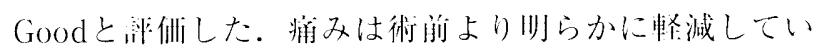

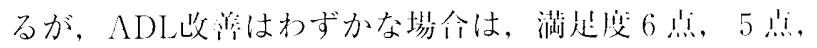

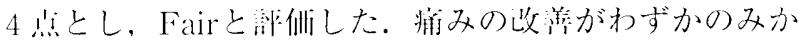

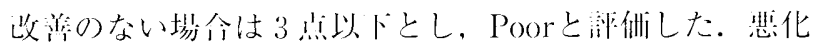

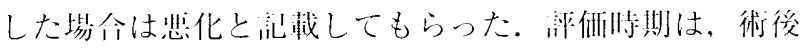




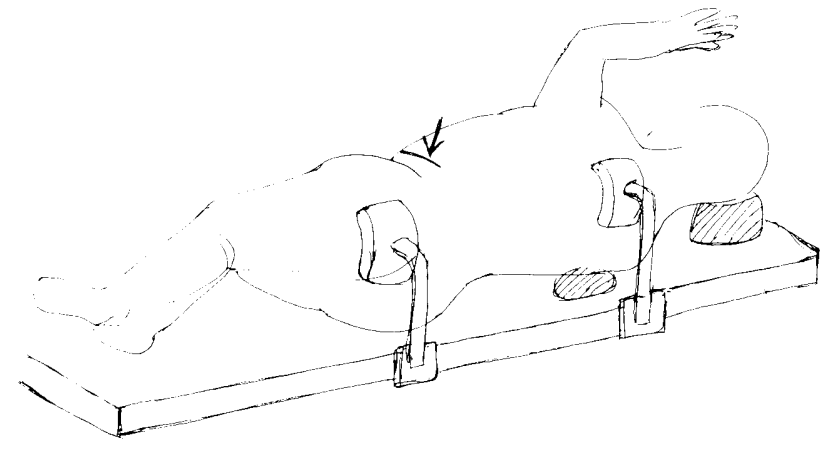

Fig.3 : Position in OR. Seven centimeter skin incision (arrow) was made just rostral to the iliac crest under the fluoroscopic control. Operator stands in the back of the patient.

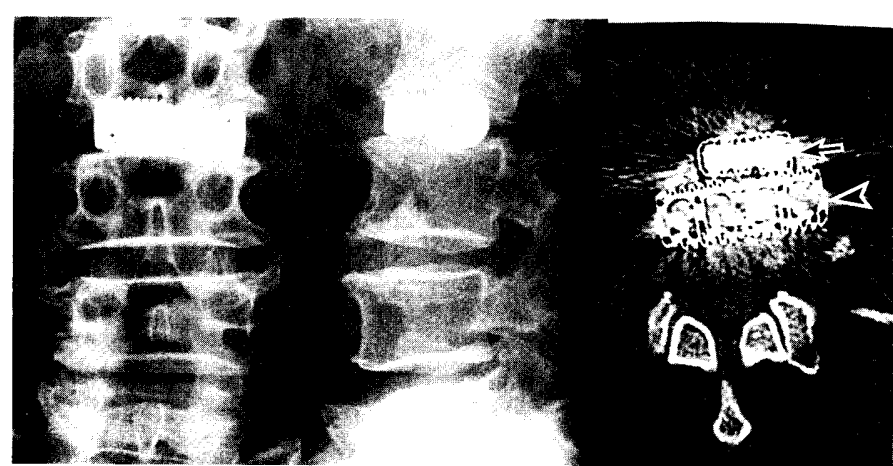

a

b

c

Fig.4 : Postoperative plain radiograph and CT. Round shape BAK cage (arrowhead) and rectangular Prospace cage(arrow) were set in position at L2-3 level.
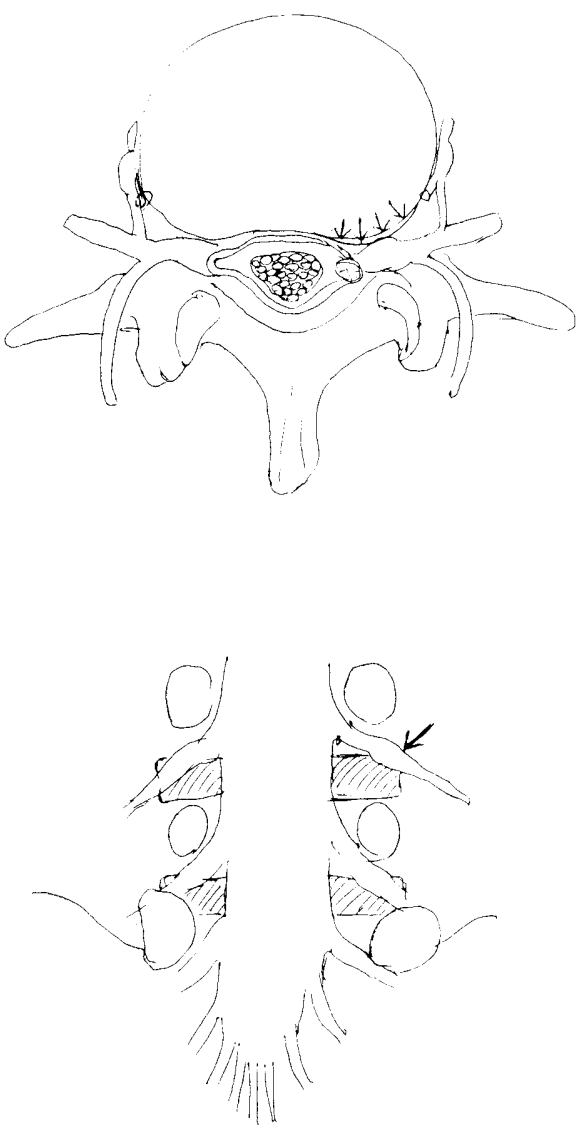

Fig.5 : Schematic drawing of the leakage area on discography. Arrows indicate the possible points where nerves compressed while injection of the dye.

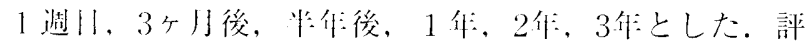
㑣は原㺫として而談で行ない，伝居などやむをえない場 仝は丁:紙か電活でおこなった（2例のみ）。

\section{$<$ 代表例 $>$}

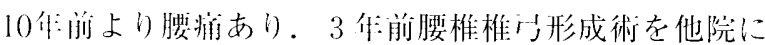
て施行きれたが，州:状の坆羓は認められなかった。その

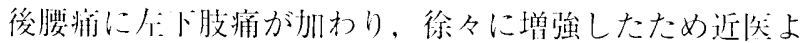

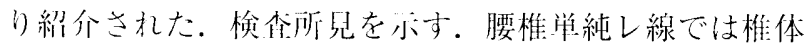
に耑梀形成在热め（Fig. 1, a,b），MRIではL2-3，L4-5で の椎润板の軽度突出を認めた（Fig. lc）。また，L4-L5で

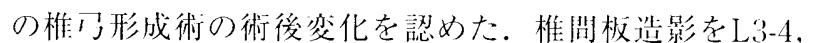
L4-5，L2-3 の順で施行した。誘発が認められたのはL2-3 であった。いもの腰痛上左ト肢痛が州现した。造影時

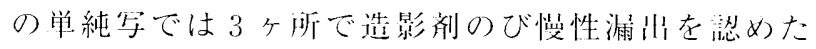

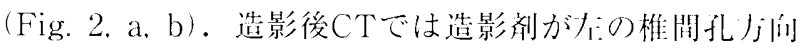

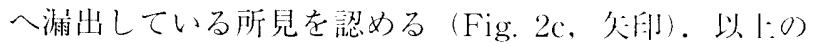

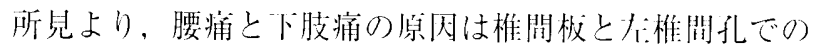
神経根症状と判断し，L2-3での椎閏枚切除と湖分老施行 した。全身林酔トで，体传は有下侧似位とした。皮切は 透視下にL2-3の椎间板に後腉膜経肺で到達する南けの位 狊にした（Fig. 3)。艾切後，3腐の筋膜を籼離し，後腹 


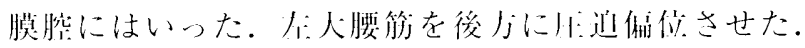

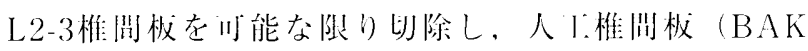

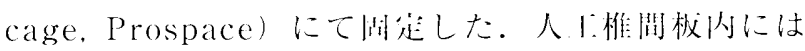

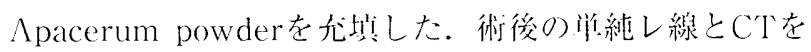

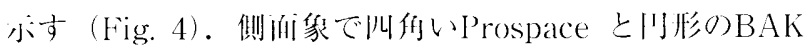
cageが垫められる。いず机もチタン製である。術後，倠 川'後より㰞性コルセット装着にて少行泎川し，術後10

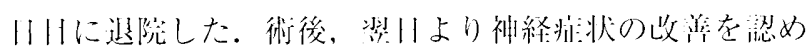

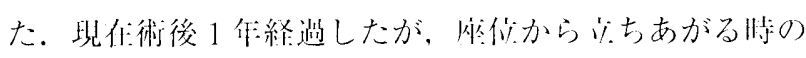

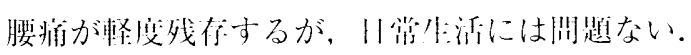

\section{結 果}

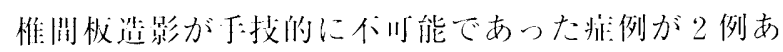

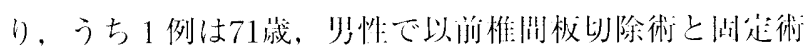
を受けている精例であった。他の1例は77筬众性で腰仙 部に人きな林擦れのある为洌であった。この2为例では，

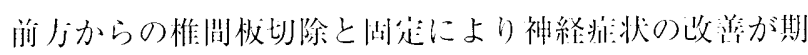

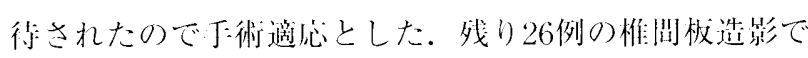

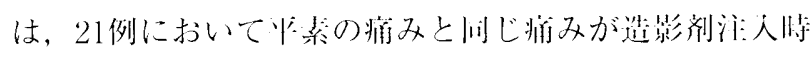
に唀発された。これ老home pain あるいは concordant

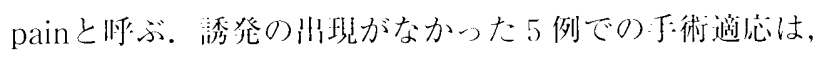

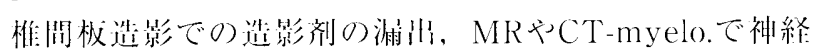

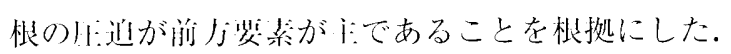

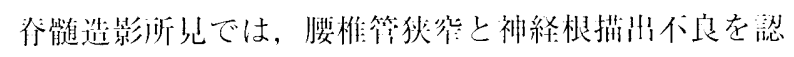

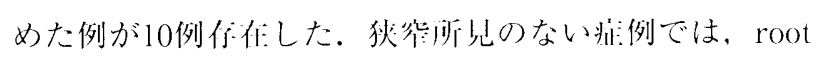

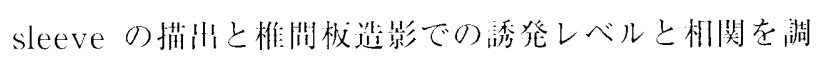
ベたが，有意な関係は見られなかった。

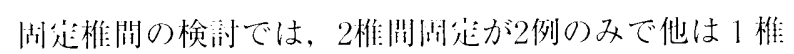

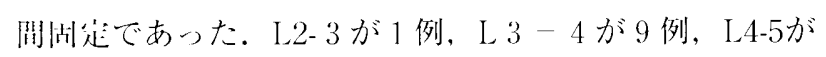
20 例，L5-6が 1 例であった。

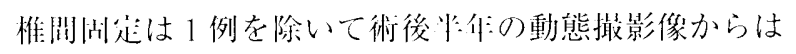

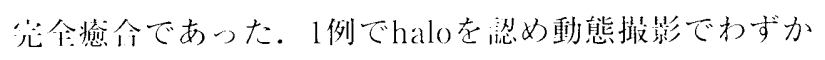
な動きをしめした。術闹JOA scoreが中垱13.8点から術

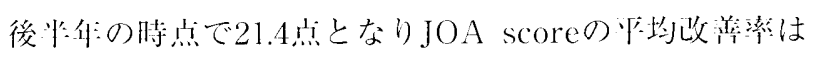

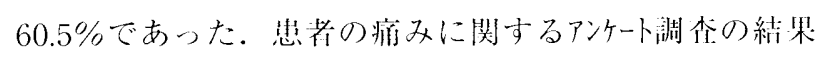
は次の道りである。28例の腰痛はExcellent 11 例, Good 14例, Fair 2 例, Poor 1 例であった. 16例の卜 肢擦は Excellent 11例, Good 5 例であった。迎跡期

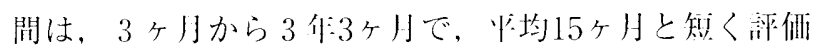
は网難である。しかし，この知剘成縜からは令後の成䋶 が期待できる。

術後半作:後の椎洞板腔の狭小化は6 例に琹め, いずれ も約 $2 \mathrm{~mm}$ の減少を小した。この6 例はcageの subsidenceと判足した。

\section{考 察}

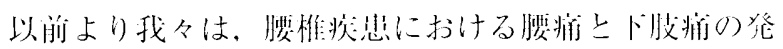

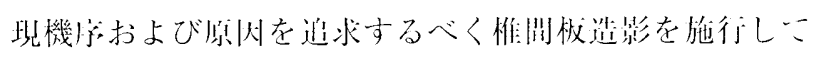

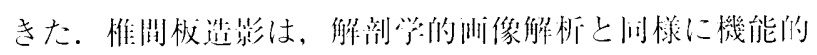

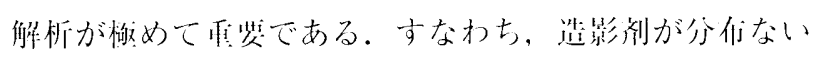

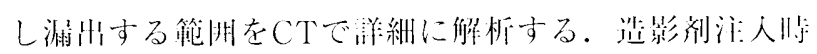

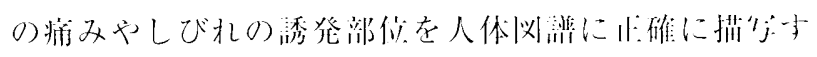

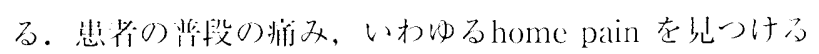

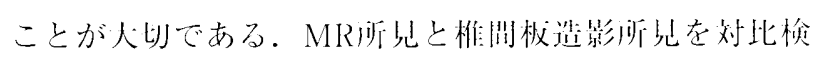

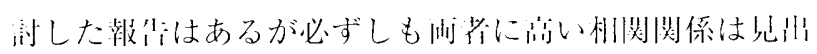

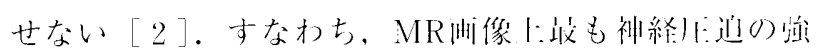

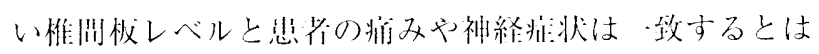
限らない。このようなdiscogenic pain は上゙の钣俈から

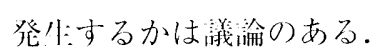

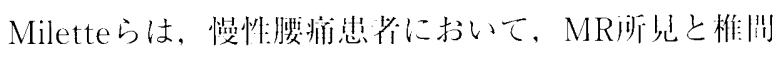

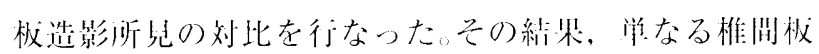

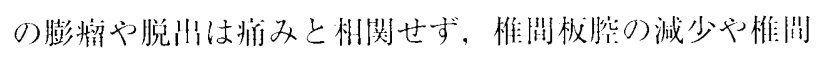
极の信多变化が为状と相関すると述べている。特に線維 輸の外僛の断裂と関係古ると絬棆した [5]. Schellhas

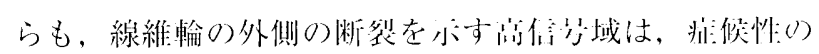
腰痛に関倸すると述べた「7]。彼らもMR所思と椎润 极造影との関係を平岁视した。

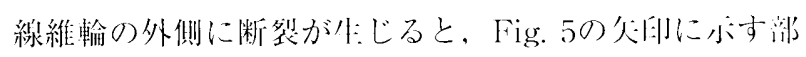

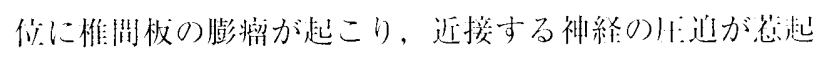
されると想分した。刚でホした部仿は, lateral recess, 椎閏板，卜関節突起によって神経が圆される川能悱り

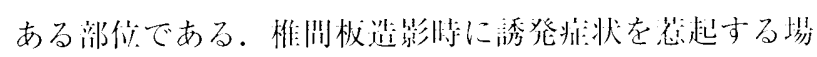

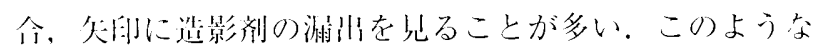

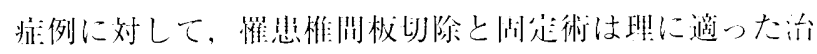

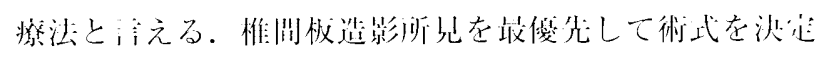
する。

このような为:例に刘しては1999作８月より本法にてた

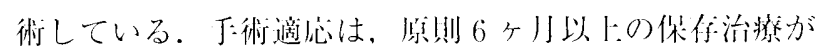

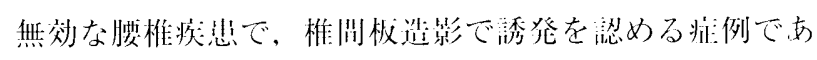

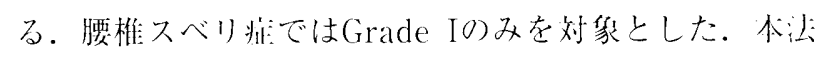

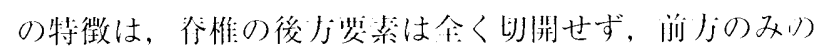
操倠老施行する焦である。

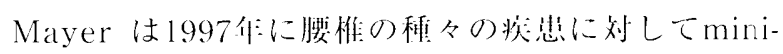

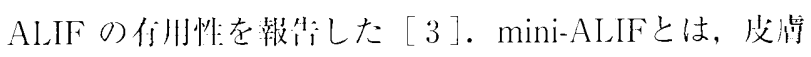

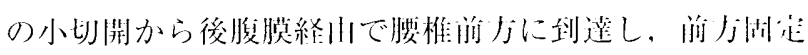

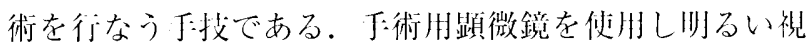


野のもとで椎間板切除後に自家骨移植を施行後, 体位を 変えて後方からpedicle screw fixation を一期的に行な う. McAfee らは, 鏡視下に後腹膜的に同様の腰椎椎間 固定と施行し, 側方から椎間板を切除し, BAK cage を 挿入し固定し, 有用性を強調した $[4]$ 。本邦では, 田 中らが腰椎変性すべり症に対しmini ALIFを行ない良好 な成績を報告している [8].

我々は両者の利点, 欠点に注目し, 脳神経外科医が慣 れている顕微鏡下で最小皮切の手術をめざし，1999年 8 月よりMayerのapproachで腰椎椎間板切除を施行し, McAfee の方法でBAK cageによる固定法を採用した. その後2001年11月より固定性強化の目的でBAK cageに 加えてProspace cageを腹側の椎間板腔に挿入する方法 を試みてきた。

いわゆる, discogenic low back pain に対してParker らは腰椎後方固定術（PLF）を施行した. 23例に対して 47 ヶの平均追跡期間の成績は, Excellent or Good 39\%, Fair 13\%, Poor 48\%であった。患者選択と労災保 証問題の患者には十分な注意が必要と結論した $[6]$. 典型的なforaminal または extraforaminal のヘルニア に対しては，固定を必要としない術式で行なうべきであ る.その他, 椎間孔部神経根障害の病態に応じた種々の 手術法があるが [1], 現時点では画一的術式はないの が現状である。

今後，中期成績にて評価する予定である，本術式での 問題点のひとつは固定椎間の椎間腔の狭小化すなわち cage subsidenceの出現である. 現時点では 6 例におい て, 約 $2 \mathrm{~mm}$ のsubsidenceを認めている。椎間孔を拡大 保持することが，本術式では生命線になるので今後の課 題である.

\section{文 献}

1. 馬場久敏: 腰椎椎間孔部神経根障害の病態諸相. 脊椎脊髄 $10 ： 625-630,1997$

2. Ito M, Incorvaia KM, Yu SF, Fredrickson BE, Yuan HA, Rosenbaum AE: Predictive sign of discogenic lumbar pain on magnetic resonance imaging with discography correlation. Spine 23: 1252-1258, 1998

3. Mayer HM: A new microsurgical technique for minimally invasive anterior lumbar interbody fusion. Spine 22: 691-699, 1997

4. McAfee PC, Regan JJ, Geis WP, Fedder I:
Minimally invasive anterior retroperitoneal approach to the lumbar spine Emphasis on the lateral BAK. Spine 23: 1476-1484, 1998

5. Milette PC, Fontaine S, Lepanto L, Cardinal E, Breton G: Differentiating lumbar disc protrusions, disc bulges,and discs with normal contour but abnormal signal intensity magnetic resonance imaging with discogenic correlations. Spine 24: 44-53, 1999

6. Parker LM. Murrell SE, Boden SD, Horton WC: The outcome of posterolateral fusion in highly selected patients with discogenic low back pain. Spine 21: 1909-1917, 1996

7. Schellhas KP, Pollei SR, Gundry CR,Heithoff KB: Lumbar disc high-intensity zone correlation of magnetic resonance imaging and discography. Spine 21: 79-86, 1996

8. 田中雅夫, 中原進之介, 小浦宏, 甲斐信生, 伊藤康夫：腰椎変性すべり症に对するmini ALIF. 脊髄外科 $15: 119-125,2001$ 


\section{Reviewer's comment：久保 和親（柇原温泉病院 脳神経外科）}

Mini-ALIFの有用性を論じた論文であり，その有用性に何ら問題のない結果と思います。筆者らは罹患部位 の決定に椎間板造影を用いてみえますが, root blockとの併用例はないようです. 28 症例中 7 例が再手術例で ある点を考え合わせますと，まずroot blockで罹患神経根の決定を行い，必要であれば椎間板造影を施行し， 椎間孔病変の性状を把握すべきではないかと考えます。つまり椎間孔病変が椎間板へルニアであるならば, Trans-pars-interarticularis approachとFar lateral discに対するapproachを組み合わせることにより rootの減 压, discectomyが可能です。この場合椎間固定は必要ありません. 今回報告された術式は, 椎間板切除により 椎間板腔の圧を下げ, Cylindrical cageの挿入によって椎間板腔の高さを確保，つまり椎間孔の拡大を図り， 神経症状を緩和するということになります。この場合椎間固定後のsubsidenceは椎間孔の再狭小化を招くこと となり, 非常に大きな問題となります。本文中に, 術後半年の時点で椎間板腔の狭小化を 6 例に認め, subsidenceによるものとの記載がありますが, Stand-alone lumbar cage fusionでは上下椎体に1mmずつ，つ まり計2mmのsubsidenceはTitanium cageを用いる以上，必ず生じるものと理解すべきです.

この術式の有用性に問題はありませんが，さらに症例を絞り込んで適応を厳密に決定する必要があると考え ます．場合によっては固定術なしで治癒し得る症例の混在があるかもしれません．長期にわたる経過観察とそ の結果の報告を希望します.

\section{Reviewer's comment：橘 滋国（北里大学医学部 脳神経外科）}

脳神経外科医に脊椎脊髄手術に精通した医師の増加は喜ばしいことである。手術手技に対する知識の普及と 技術の向上は日々進歩しつつある。一方，手術適応の決定はいまだ個々の医師に任されている部分が多く，や やもすると，過㮃適応のきらいが無いとは言いきれない。この論文に記載された手術はその適応の決定が易し くないものである．腰痛のみで脳神経外科を受診する患者数は限定されていると考えられるが，いわゆる馬尾 性間歇性跛行は我々が日常診療の中で遭遇する頻度が日々高くなってきている．本論文では馬尾性間歇性跛行 との鑑別が明確ではないが，腰痛と下肢痛を訴える患者の中にdiscogenic pain と考えられる症例は確かに存在 する．椎間板造影とこの手術は，こうした患者の診断と治療に有効であると著者は結論している．慎重な手術 適応の決定と, この手術方法の習得は今後我々脊椎脊髄外科医にとって必要なオプションの一つになろう. 